\title{
Using magic trick problem-based activities to improve engagement in a listening class
}

\author{
Ikhsanudin Ikhsanudin, Sudarsono Sudarsono, Urai Salam \\ Faculty of Teacher Training and Education; Universitas Tanjungpura - Indonesia \\ ikhsanudin@fkip.untan.ac.id
}

\begin{abstract}
Student engagement is a crucial topic in the discussion of teaching and learning process quality, including at a tertiary level. The goal of this classroom action research is improving the engagement of the students in the English education department in a listening class through "magic tricks" problem-based activities. This research was conducted at the College of Teacher-Training and Education of Universitas Tanjungpura (FKIP UNTAN), Pontianak - Indonesia, in October-November 2018. The research was conducted in two cycles and the data were collected through participant observation. In three stages of analysis (initial coding, focused coding, and explanation), this research successfully improved the students' engagement. The students' engagement was improved substantially in the second cycle after the magic trick activities were combined with pair discussion, group discussion, and cross-group discussion. The magic trick problem-based activities were an important factor that could invite the students' intellectual engagement, whereas the discussion activities improved the students' emotional and behavioral engagement. The creative variation in the discussion stage had improved the students' engagement considerably.
\end{abstract}

\section{Keywords}

magic trick; problem-based; engagement; listening

\section{doi:http://dx.doi.org/10.26418/jeltim.v1i1.31620}

\section{INTRODUCTION}

Amongst important student problems in classroom interactions is engagement. When the students are engaged, the classroom interaction will be vivid and enjoyable. Having vivid and enjoyable classroom interaction will optimize their learning. An expert defined students' engagement as the interaction between students and their institution involving the time, effort and other relevant resources to optimize the student experience, improve students' learning outcomes and development, and increase performance and reputation of the institution (Trowler, 2010). However, it is widely agreed that getting the students engaged in the classroom activities is challenging. The students' engagement is complicated to attain and to maintain. Nevertheless, it still needs to be managed for successful teaching.

This classroom action research was conducted with a Class A of Listening for General Communication Course at FKIP Untan in the academic year 20172018. The course was offered as a mandatory class to the first semester students, which consisted of 24 students. All of the students were newly graduated from senior high schools in different counties and cities in Kalimantan Barat (West Kalimantan). The class took place at the FKIP Language Laboratory twice a week time with each session being held for one hundred minutes. The setting of the lab was very conventional. All the students had to sit at the booth and faced the teacher's console near a central white marker board. Messy cables and non-functioning booths were also conditions that never changed. To support the 24 students, the lab had only 20 booths, but only half of them functioned.

It was a challenge to teach listening in a nonfunctioning language lab to new students that had not known one another. At the beginning, the students were excited about being new students of the most prestigious university in their province and the class took place in a language lab. It was more than exciting for them because not many of them had ever seen a language lab. However, they felt the excitement only before trying to use the lab. Even though in the interview most of them said they were happy to study in the listening lab, from observing their expressions, the researcher could find that they were disappointed. As new students, they tried to enjoy the class, but starting in the second meeting they were less engaged. Up to the fourth meeting, only three students participated actively by raising hands, asking questions, and answering questions. The lecturer tried to cheer up the class by selecting 
interesting audio-video tracks for them to listen to, but only four students were engaged at most.

After trying several techniques to engage the learners which were not very successful, the teacher offered a "magic trick" game and the learners responded very enthusiastically. The magic trick was offered by referring to a previous study on the opportunity of developing English magic tricks as problem-based activities to enhance students' engagement (Ikhsanudin, 2017). The classroom action research (CAR) using the magic trick game was conducted to contribute to the knowledge base by exploring an idea to use magic tricks as problembased activities in a higher education setting. It was also intended to address the use of magic tricks as problem-based English activities to engage FKIP UNTAN students.

The importance of student engagement has become the focus of attention in the higher education. Applying appropriate and fun strategies that can fit the university communities and the learning needs of students is expected to increase students' engagement. One of the strategies that can be utilised based on its prospect to engage the higher education students is magic tricks as problem-based activities. The classroom action research is, therefore, conducted to directly address a question: in what ways were the use of magic tricks as problem-based activities able to engage FKIP UNTAN students in increasing their listening skills in a general communication class?

The purpose of this classroom action research is to explore the use of magic tricks as problem-based activities that may have contributed to getting students engaged in the teaching-learning process in the higher education setting. The study was not intended to investigate whether this strategy can improve the students' listening skills in general communication. However, it is expected that, by getting engaged in a set of the teaching and learning process, the learners' listening skills will improve.

There are three dimensions of engagement indicators that are used in this research, namely: behavioral engagement, emotional engagement, and cognitive engagement. The behavioral dimension of engagement is indicated by the learners' attendance to the class, involvement the classroom activity vividly, and absence of disruptive or negative behavior. The emotional dimension of engagement is indicated by affective reactions of interest, enjoyment, and sense of belonging. The cognitive dimension of engagement is indicated by the students' learning and efforts to go beyond the requirement or to relish challenge.
The CAR of using the magic tricks as problem-based activities to engage FKIP UNTAN students is important for several reasons. First, this CAR provides information on the issues of student engagement in the higher education that can help to overcome students' engagement problems in the communities of The Ministry of Research, Technology and Higher Education (KEMENRISTEK). Second, this CAR provides information on the use of magic tricks as problembased activities to engage FKIP UNTAN students that would be beneficial for Tanjungpura University (UNTAN). Third, the findings of this CAR are beneficial for the lectures in UNTAN, especially the lectures in FKIP UNTAN, because this research would provide the necessary information to solve their problem to engage students.

This CAR showed that the use of the magic tricks as problem-based activities would be able to engage FKIP UNTAN students. This research was limited to the review of student engagement and the using of English magic tricks as problem-based activities in listening for a general communication class. It can be expected that the improved students' engagement will lead to the improvement of their listening skills.

\section{THEORIES}

At the higher education level, educators and others have advanced educational stances supporting the conception that student engagement needs to be realized. According to Govender (2012), students can perform well academically if they are engaged with the materials. Also, it is essential to have authentic and extensive student engagement in higher education so that both quality and the scale required for widespread-affordable attainment can be obtained (the National Survey of Student Engagement, 2013). Still, it is widely known that student engagement has become problem due to the rise of mass and universal forms of higher education (Kahn, 2011).

One of the original aims of this CAR is to provide educators in higher education settings a solution to overcome the problem related to student engagement. Theories identified early on in the study related to this original aim will be student engagement. Student engagement is the interaction between students and their institution involving the time, effort and other relevant resources to optimize the student experience, improve students' learning outcomes and development, and increase performance and reputation of the institution (Trowler, 2010). He adds that student engagement is more than the students' involvement or participation. It has three dimensions that represent a form of engagement: (a) Behavioral engagement, which 
typically relates to behavioral norms. Therefore, students who have this engagement will attend to the class, become involved in the classroom activity vividly, and demonstrate the absence of disruptive or negative behaviour; (b) Emotional Engagement, which refers to affective reactions (i.e., interest, enjoyment, or a sense of belonging); and (c) Cognitive Engagement, meaning that students would be invested in their learning, would seek to go beyond the requirement, and would relish challenge (p.5).

Moreover, according to Axelson and Flick (2011), student engagement is the involvement and interest of students in learning and their connection to their classes, their institution, and their friends. From the student engagement descriptions of Trowler (2010) and Axelson \& Flick (2011), it can be determined that student engagement relates to how the students pay attention to and feel interested in the learning activities that teachers prepare, and how they interact with their educational environment.

Student engagement is regarded as having a significant influence on achievement and learning; hence, many scholars have theorized and researched about it (Kahu, 2011). It has also become the concern of the higher education, since students can perform well academically if they are engaged with the materials (Govender, 2012). Consequently, it is essential to have authentic and extensive student engagement in higher education so that both quality and the scale required for widespread-affordable attainment can be obtained (the National Survey of Student Engagement, 2013). However, student engagement is challenging. It is complicated to attain and to maintain. Also, it has become a problem due to the rise of mass and universal forms of higher education (Kahn, 2013).

The other aim of this CAR is to explore a strategy to engage students in higher education. This CAR therefore proposes magic tricks as problem-based activities to engage students. The reason why using the magic tricks can make the students engage in the teaching-learning process is that magic art has impossibility and amusement that are able to attract people's attention and to hold it (Spencer, 2012). Moreover, it is widely known that magic may be the oldest and the most universal of the performing arts (Christopher \& Christopher, 2005 as cited in Spencer, 2012, p. 47) that is considered as a work produced by human creative skill and imagination, and social life as well (The New Oxford American Dictionary, 2010 as cited in Spencer, 2011, p.88).

The competence of magic to attract people's attention and to hold it is the foundation of why magic tricks could be a potential strategy to engage students. It has been approved by Ogren (2014) who applied magic in his classroom. He said that magic is an effective strategy to motivate and inspire students to read, advance their physiotherapy, build confidence, and think creatively. He adds that magic can make classrooms more fun and enjoyable. Even though the classroom becomes very enjoyable and interesting, the implementation of magic does not give negative effects to the comprehension of the student towards the material (Moss et al., 2016).

The primary goal of this CAR, therefore, becomes to explore the use of magic tricks as problem-based activities to engage FKIP UNTAN students in a general communication class. Magic tricks which are amusing and can arouse the curiosity of students are believed to be able to meet the qualifications of strategies that can engage the students. Moreover, magic tricks can also enhance teacher engagement with the materials and activities that they have prepared. The higher teacher engagement is, the better student engagement will be; accordingly, Bryson and Hand (2007) state that students barely engage with the classroom activities unless their teachers engage with them and the activities.

A number of studies on student engagement have been conducted to discover the ways to achieve it. Krause (2005) shares ten working principles for enhancing student engagement, one of which is to provide targeted self-management strategies. Then, Taylor and Parsons (2011) state that making university communities fit the learning needs of students seems crucial and promise to organize how the study of student engagement will be carried out in the future. Moreover, Davis (2013) conducted a research study that resulted in outcomes proving that developed games can increase student engagement as well as cover the content of the lesson. These various research studies have been conducted to examine the ways to achieve student engagement. The evidence is almost uniformly in conformity in indicating that student engagement could increase by applying an appropriate and fun strategy that can make educational environments fit the learning needs of students.

Many studies have been conducted to explore whether magic tricks can be implemented in achieving student engagement in the teachinglearning process. Above, there is some research on student engagement mentioned. First, Krause (2005), in his research study on student engagement, states that one of the working principles for enhancing student engagement is to provide proper strategies. The conclusion of these three studies is that student engagement could be achieved by applying an appropriate and fun strategy that can make educational environments fit the learning needs of students. Therefore, the use of magic tricks 
as a strategy to achieve student engagement is proposed.

In the section on the conceptual framework above, research conducted by Kevin Spencer was mentioned. Spencer (2012a) researched the implementation of magic tricks in the teachinglearning process. In his research, he discovered that his Hocus Focus curriculum - a magic trick that he examined - demonstrated improvement in specific areas for special learners and teacher efficacy, proficiency, and satisfaction. Furthermore, Hocus Focus also gave psychological, behavioral, and cognitive benefits for students. In another research study with a similar topic, Spencer (2012b) found that Hocus Focus also impacted all three domains of learning, resulting in student improvement in on-task behavior, planning and sequencing, socialization and meaningful conversation, and fine motor skills/dexterity.

Then, a couple of years previously, In (2009) examined the implementation of origami and magic tricks in the teaching-learning process. The research resulted in an outcome that showed magic tricks successfully appealed to the students because of the mysterious and spectacular outcome of magic tricks that could trigger students' curiosity and ability to impress their peers. Furthermore, in 2013, Crossman conducted a project that examined whether magic could engage and create a positive learning environment. The results of her project determined that magic could assist with creating a positive learning environment. The next year, Ogren researched the implementations of magic tricks in the teaching-learning process. Ogren (2014) in his research found out that magic has been an effective strategy to motivate and inspire students to read, advance their physiotherapy, build confidence and think creatively. It also creates a fun and enjoyable classroom environment where students want to be. Moreover, it was also shown that magic tricks are effective for collaborative learning as demonstrated in research performed by Adipramono \& Nindhita (2016).

However, Moss et al. (2017) managed research that showed a result that was slightly different from the outcomes of other research. In their research, the result shows that magic tricks could diminish the subsequent need for cognition but do not affect comprehension. The research also shows that magic tricks tend to diminish engagement with subsequent material (Moss et al., 2017).

Overall, research conducted showed that magic tricks have potential to be used in teaching-learning activities. In consideration of good outcomes from previous studies, an inquiry about the implementation of magic tricks in teaching learning activities will be continued. However, in this future research, the focus of the research will be on the student engagement. It will examine the extent to which the implementation of magic tricks can get the students engaged in the teaching-learning process.

\section{METHODOLOGY}

This research was conducted using action research, specifically classroom action research (CAR) method. There were two cycles of CAR and every cycle consisted of four steps: planning, acting, observing, and reflecting.

The data that were collected in this CAR were the students' engagements during the teaching and learning process. In the baseline, the engagement data were collected in the teaching-learning process during the pre-research observation by the researcher. In the middle, the students' engagement data were collected during the acting process in the first and second cycles, or so. The final data collection was the situation in which most of the students were engaged in the teaching and learning process. The final qualities of engagement were possibly found in the third, fourth or fifth cycle of the CAR.

The data for this research were collected through observations. The lecturer observed the students' activities by performing his job as a lecturer in the classroom. Two appointed students collected the data while performing in their role as the students of the class. The instruments used to collect the data were: (1) a set of observation sheets used by the lecturer, appointed students and collaborator; and (2) a set of observation checklists used by the collaborator.

The data analysis techniques used were as follows: First, descriptive statistics (mainly percentages) were used to analyze the data that were collected using an observation checklist. Second, coding was used to analyze the data that were collected using an observation sheet. Third, content analysis was used to analyze the data were collected using an observation sheet. Fourth, focus group discussions (FGD) were used to crosscheck all the collected data by the lecturer, appointed students, and collaborator. FGD will be done during the reflection stage of each cycle.

\section{FINDINGS AND DISCUSSION}

The findings of this CAR are organized based on the progress of improving the students' engagement. They begin from the findings of the baseline and then progress to the findings of the first cycle and the findings of the second cycles. 


\section{a. Baseline}

In the baseline situation, before the CAR had been conducted, it was found that the students were not engaged in the classroom activities. There were two meetings of participatory observation by the lecturer on the first and the second meetings (Tuesday at 09.20-11.00 and Thursday at 12.30-14.10). All students attended the meetings. They looked very enthusiastic before entering the lab, up to the first 40 minutes of the first meeting. Knowing most facilities could not work properly and the lab room looked messy with unorganized facilities and cables, they found it difficult to become engaged with the activities. The lecturer tried to adjust the activities to the situation by having teacher-centered two-way interactions. Most of the activities were listening exercises and word-sentence recognition drills. The materials were some selected audio-video files downloaded from Youtube. The learners tried to become engaged by answering questions, but it did not seem very easy for them to do so. The participant observer found that the learners' linguistic prior knowledge was too far below the requirements. Only three students could participate well in the interactions.

In the second meeting, the participant observer (lecturer) tried to do some scaffolding by introducing some related linguistic knowledge, such as vocabulary. The materials were some audio-video files downloaded from Youtube, but of a different topic from the previous meeting. Most students did their best to do the exercise. A larger number of students could answer the questions, but only four students (including the three that were engaged in the previous meeting) raised a hand to answer confidently. This second meeting could produce very little improvement in engaging the students. The rest of the students looked quiet and afraid to raise their hands even though many of them had written their answers in their books. When the lecturer asked them to interact with one another, it was discovered that they had not known one another quite well. The situation was not ideal for a language skills class, particularly for listening class. The learners experienced difficulty getting engaged in the classroom activities.

\section{b. Cycle One}

The first cycle took place in the fourth meeting, on Thursday at 09.20-11.00. In the planning, it was written that the class would discuss a topic on campus life. Problem-based activities had been prepared by the lecturer. The learners' had been directed to download four files on the topic and were given freedom to choose the files that met their interests and level of proficiency. They had two days to make a summary of the contents of each audio- video file. Each summary was to be hand-written within 60-80 words. The lecturer prepared a magic trick set or properties a magic trick tutorial audiovideo. Two students were assigned to observe their classmates' engagement. So, there were three participant observers: two students and the lecturer.

The observation data resulting from the three participant observers are summarized as follows. All students were ready with their summaries as instructed by the lecturer. Before the class started, the lecturer played a magic trick game to engage the students. The students were very enthusiastic in watching the demonstration. After the demonstration, the lecturer asked whether the students knew the magic secret. No single student could answer, but most of them showed their curiosity. When most students were curious, the lecturer asked them to listen to the audio tutorial. Because of the curiosity, the students tried their best to understand the magic secret by listening to the file carefully. The lecturer played and replayed the file many times and the students were highly engaged and never felt bored of being engaged in the classroom activities. Only one student could reveal the magic secret. Other students were getting more curious. The anticlimax of the magic trick game was watching the tutorial audio-video together. The activity was ended up with watching together: the lecturer led an activity of matching what the students had listened to and what they had watched.

The magic trick game then was followed up with listening to one of audio-video files that were prepared by the students. This was also problembased comprehension activity. Before listening, the students were exposed to five comprehension questions, such as the main topic, detailed information, and inference. The students wrote down and discussed the meaning of the questions with the lecturer. After confirming that most students understood the meaning of the questions, the lecturer asked the students who summarized the audio-video to be the "assistants" in playing the audio-video file. The lecturer had the audio-video played twice without displaying the picture/vidio on the screen. They only listened to the audio and were challenged to answer the questions after listening to it. Most students raised their hands but mostly only could answer the first questions. The three students tried to answer other questions. The lecturer did not respond "right" or "wrong." To increase the learners" comprehension, then, the lecturer had the assistants replay the audio twice. More students raised their hands to answer questions $2-5$. The resolution was answering the questions together by replaying the related part repeatedly. 
In the process of reflection, the lecturer researcher found some interesting facts as follows: The students' behavioral engagement could be observed from their full attendance and activities of raising hands. Their attendance was very good, but the researcher needed to determine whether their very good attendance would be consistent or was just the phenomenon of the excitement of being new students. The students also raised their hand when the lecturer asked them the first questions. This was also good, but not good enough. They only raised their hands in preparation to answer the first question because the question was a general question. This response was not excellent and needed to be improved. Their status as new students might have been the reason. The students had not previously known one another very well. To improve the behavioral engagement, they needed to be grouped and stimulated to work together within the group. To maximize their behavioral engagement, they also needed to be directed to do an intergroup discussion or cross-group discussion.

The magic trick game made them engage emotionally. The researcher found that more than half of the students felt curious and optimistic. The properties of the magic trick game were simple, and the trick seemed easy to reveal. Their expression of curiosity and confidence in solving the problem were undeniable. Only five students were given the magic kit to try to solve the magic trick problem, but many of their classmates appeared to want to try it. However, when there were exposed to the next activity, answering comprehension questions on campus life, they were not as engaged as they were in the magic trick game activity. The topic might have been not as impressive as a magic trick, or it might have been difficult with more questions. Grouping would possibly help. By working in groups they would be able to ask their friends and to discuss in the relatively freer atmosphere.

The students' cognitive engagement in this first cycle was excellent. They were challenged to solve the magic trick problems before being challenged to answer comprehension questions. They were trying to figure out the answer. However, their schemata were not quite adequate enough to overcome the difficulty. Many questions were not answered. There should be a strategy to solve the situation. One of other the possible ways would have been modifying the questions or down-grading the task's complexity.

\section{c. Cycle Two}

The second cycle was prepared in three days after the researcher produced a reflecting description. It was planned that the topic of listening would be "Being New University Students" and before the primary activity there would be a magic trick game again, but there would be some modifications of the classroom activity. The students' participation would be more than in the previous cycle. It was planned that it would be the students who would perform the magic trick game who should play the tutorial audio and who would play the non-magic trick audio-video file. The magic trick game would be played by a pair of students. They also would play the tutorial audio. Meanwhile, the non-magic trick audio-video file would be played by a student that would not have played the magic trick. The audio would also be taken from the students' collections. One of the students (who would play the audio) would have listened to and summarized the contents of the audio-video. This setting would be important to improve the whole class engagement. There would be two evaluations in the meeting. The first was on the students' engagement (through participant observation) and the second was on the students' ability to answer comprehension questions.

The teaching strategy would be similar to the procedure that had been used in cycle one, problembased strategy through problem-based activities. The learners' would have to download four files on the topic of being new university students and were also given freedom to choose files that met their interests and level of proficiency. They had three days to produce a summary of the contents of each audiovideo file. So, there would be four summaries that should be produced by each student. Each summary should be hand-written within $60-80$ words. The students had been assigned to prepare magic trick games, and they would perform these in front of the class. There would be only one pair of students that would present at every meeting. They would be selected randomly.

After the action and observation stage that took place simultaneously, the observation data that resulted from the three participant observers are summarized as follows: After being greeted by the lecturer warmly, all students submitted their summaries, as instructed by the lecturer, at the beginning of the class activities. The class was started with some warm-up questions about the prepared magic trick. This was done to make the rest of the students curious. Then a magic trick game was played by a pair of students. The rest of the students were very enthusiastic in watching the demonstration. After the demonstration, the lecturer asked whether the students knew the magic secret. Most of the students showed their emotional engagement and curiosity and tried to raise their hand although they were not very confident about their answers. When a student was appointed to reveal the secret because he seemed to raise his hand, he answered: "Not very sure, sir. I want to listen to the tutorial." When most students were curious, the lecturer asked them to 
listen to the audio tutorial. Because of the curiosity, the students tried their best to understand the magic secret by listening to the file carefully. The students played the file three times, and they were highly engaged and did not feel bored of listening to the audio tutorial. After listening, nine students raised hands confidently but the rest just smiled and got more curious because they saw their friends raising their hands confidently. The audio was played again twice and most students listened curiously, including those who raised hands confidently. It seemed the tutorial was not very easy for most students. The lecturer, then, asked them to discuss the magic trick problem in groups of three to four. Some groups sounded very noisy debating the secret and ended their discussion with bright smiles. Other groups were still very serious. Then the lecturer asked the students that had not got the answer to move to any group that they wanted to. The classroom was getting noisier but very dynamic. Finally, most students were satisfied. They got the answer. Similar to what happened in the first cycle, the anticlimax of the magic trick game was also watching the tutorial audio-video together. The students were supported to confirm what they had already got from the discussion process and what they were watching on the screen.

The magic trick game then was followed up with listening to one of the audio-video files that were prepared by the students. This was also a problembased comprehension activity. Before listening, the students were exposed to five comprehension questions, such as the main topic, detailed information, and inference. The students wrote down and discussed the meaning of the questions with the lecturer. After confirming that most students understood the meaning of the questions, the lecturer asked the students who summarized the audio-video to be the "assistants" in playing the audio-video file. The lecturer had the audio-video played twice without displaying the video on the classroom screen. The students were challenged to answer the questions after listening to the audio twice. Most students raised their hands but mostly only could answer the first questions. The three students tried to answer other questions. The lecturer did not respond "right" or "wrong". To increase the learners" comprehension, then, the lecturer had the assitants replay the audio twice. More students raised their hand to answer questions 2-5. The resolution was answering the questions together by replaying the related part repeatedly.

In the process of reflection, the lecturer researcher found some interesting facts as follows. The students' behavioral engagement could be observed from their full attendance, activities of raising hands, group discussion, and cross-group discussion. Their attendance was excellent. They tended to be consistent in attending the class. More students raised their hands when the lecturer asked them the questions, not only the first ones. This was also excellent. Even though the students had not known one another very well, through group discussion and cross-group discussion, they could interact very well. So, their behavioral engagement improved.

In the second cycle, the students were much more engaged emotionally. Magic trick games made them engage emotionally. The researcher found that most of the students felt curious and optimistic. The kits of the magic trick game were simple and the trick seemed easy to reveal. Moreover, the magic trick game was performed by their classmates. Their expression of curiosity and confidence of solving the problem were very obviously emotionally engaged. When they were exposed to the next activity, answering comprehension questions on being a new university student, they were also as engaged as they were in the magic trick game activity. The topic might have been interesting; the questions were not very difficult. Grouping had helped them get engaged much better. By working in groups they were able to ask their friends and to discuss in the relatively freer atmosphere.

The students' cognitive engagement in this second cycle was exciting. They were challenged to solve the magic trick problems before being challenged to answer comprehension questions. They were trying to figure out answers. Even though their schemata seemed not quite enough to reach the difficulty, the downgraded questions and group working (including cross-group working) had helped them very much. More questions were answered better than the questions of the first cycle.

Creative implementation of the magic trick game has improved the students' engagement in Universitas Tanjungpura's listening class. Not only has the ceative implementation improved a behavioral aspect of engagement but it has also improved emotional aspects and intellectual aspects of engagement. Creative implementation means implementing in various ways and combining the magic trick performances or games with other techniques of teaching. The creative implementation more effectively engages the students when it invites the students' participation.

In this CAR, the creative implementation of magic tricks in a general listening class successfully improved the students' engagement. Of course, it cannot be generalized to a wider scope. The truth that magic trick games engage the audience has been proven in many investigations. This CAR implemented the magic trick game in a specific class that had a specific problem. The students' 
engagement could be improved using the magic trick implementation in this CAR due to several reasons.

Language is a means of communication, and any communication is considered effective, if it is authentic. An authentic communication has three important aspects, namely: information gap, choices, and feedback. In the magic trick game, at least there is always an information gap. The performer knows, but the audience does not, what the magic secret is. The audience's curiosity will invite their lateral thinking, that is looking for or figuring out as many potentail answers as possible. Those are the choices. When answering the questions, the audience gives feedback. Then, when the performer responds to the questions, that is also feedback.

Learning will be enjoyable if it accommodates four learning styles, namely: auditory, visual, kinesthetic, and intellectual. Auditory learners like listening to information and learning through listening will be easy for them. A visual learner will learn better through seeing or watching or reading; using eyes. A kinesthetic person tends to move and cannot stay calm for a relatively long time. S/he also likes changes. This type of learner is a dynamic learner. Meanwhile, an intellectual learner likes problemsolving activities. S/he likes thinking. One learner may have more than one learning style. The magic tricks that were performed in the two CAR cycles promote learning that may satisfy the different learning styles of the learners. The introduction of the magic trick game invited the learners to think about the magic secret. This invited intellectual learning. The performance invited visual plus intellectual learning. The performers' voices and the tutorial audio (usually with music: intro and coda) promoted audio learning. The groupings and crossgroup discussion made the learners move and promote kinesthetic learning.

\section{CONCLUSION}

Creative implementation of the magic trick game in a two-cycle CAR has successfully improved the students' engagement in Class A of the listening for general communication course of the College of Teaching and Education of Universitas Tanjungpura. The creativity in the implementation has found that warm-up interaction, group work, cross-group work, and student class performance could maximize the students' behavioral and emotional engagement both in magic trick tutorial listening and other audio texts listening. The creative strategy in this CAR also has promoted better learning to students of different learning styles, such as auditory, visual, kinesthetic, and also challenged their intellectual ability.
Implementation of magic tricks to engage learners in classroom interaction is a good choice for creative teachers. To maximize the effect of the magic trick strategy, the teacher must always control the classroom activities in such a way that the engagement parts and the learning parts are proportional. A teacher or lecturer needs to assess the quality of engagement and learning in every episode of his/her classroom interaction. Some issues that are very useful to consider in implementing this strategy are comprehensible input, group dynamics, authentic communication, and learning styles.

\section{REFERENCES}

Axelson, R., D. \& Flick, A. (2011). Defining Student Engagement. Change: The Magazine of Higher Learning, 43(1), 38-43. doi: http://dx.doi.org/10.1080/00091383.2011.53309 6

Govender, C., M. (2012). Motivation of higher education students: A single student engagement case study. The Independent Journal of Teaching and Learning, 7, 14-23.

Ikhsanudin, I. (2017). The possibility of developing English magic tricks problem-based activities to enhance senior high school students' engagement. ICoTE Proceedings, 1, 28-34.

In, V. (2009). Using origami and magic tricks to teach English. The Internet TESL Journal, 15 (2). Retrieved from http://iteslj.org/Techniques/InOrigami.html

Kahu, E., R. (2011). Framing student engagement in higher education. Studies in Higher Education, $38 \quad$ (5), 758-773. doi: https://dx.doi.org/10.1080/03075079.2011.5985 05

Kahn, P., E. (2013). Theorising student engagement in higher education. British Educational Research Journal, 40(6), 1005-1018. doi: http://dx.doi.org/10.1002/berj.3121

Krause, K. "Understanding and Promoting Student Engagement in University Learning Communities" (2005). Center for the Study of Higher Education. Paper.

Krause, Kerri-Lee, Coates, \& Hamish. (2008). Students' engagement $\mathrm{t}$ in first-year university. Assessment and Evaluation in Higher Education. doi: https://doi.org/10.1080/02602930701698892

National Survey of Student Engagement. (2013). A Fresh Look at Student Engagement - Annual 
Results 2013. Bloomington, IN: Indiana University Center for Postsecondary Research.

Moss, S., A., Irons, M., \& Boland, M. (2016). The magic of magic: The effect of magic tricks on subsequent engagement with lecture material. British Journal of Educational Psychology, 87(1), 32-42. doi: https://dx.doi.org/10.1111/bpjep.12133

Ogren, K. (2014). Magic as an effective teaching strategy. Retrieved from https://dspace.libary.uvic.ca/

Spencer, K. (2012a). Hocus Focus: Evaluating the pedagogical implication of integrating magic tricks in classroom instruction. Journal of the International Society for Teacher Education, 16(2), 45-54
Spencer, K. (2012b). Hocus Focus: Evaluating the academic and functional benefits of integrating magic tricks in the classroom. The Journal of the International Association of Special Education, 13(1), 87-99.

Taylor, L. \& Parsons, J. (2011). Improving Student Engagement. Current Issues in Education, 14(1). Retrieved October 2, 2018 from https://cie.asu.edu/

Trowler, V. (2010). Student Engagement Literature Review (November 2010). Lancaster University, Department of Educational Research. Lancaster: The Higher Education Academy. Retrieved October 2, 2018, from https://www.heacademy.ac.uk/system/files/stud entengagementliteraturereview_1.pdf 
